-- Supporting Information --

\title{
Dry-Processed, Binder-Free Holey Graphene Electrodes for Supercapacitors with Ultrahigh Areal Loadings
}

Evan D. Walsh, ${ }^{1}$ Xiaogang Han, ${ }^{2}$ Steven D. Lacey, ${ }^{1,2}$ Jae-Woo Kim, ${ }^{3}$ John W. Connell, ${ }^{4}$ Liangbing $\mathrm{Hu},{ }^{2,}$ and $\mathrm{Yi} \mathrm{Lin}^{3,5}$,*

${ }^{1}$ NASA Interns, Fellows, and Scholars (NIFS) Program, NASA Langley Research Center, Hampton, Virginia 23681; ${ }^{2}$ Department of Materials Science and Engineering, University of Maryland, College Park, MD 20742; ${ }^{3}$ National Institute of Aerospace, 100 Exploration Way, Hampton, Virginia 23666-6147; ${ }^{4}$ Mail Stop 226, Advanced Materials and Processing Branch, NASA Langley Research Center, Hampton, Virginia 23681-2199; and ${ }^{5}$ Department of Applied Science, The College of William and Mary, Williamsburg, VA 23185

*To whom correspondence should be addressed: Y.L.: yi.lin-1@ nasa.gov; L.H.: binghu@umd.edu 


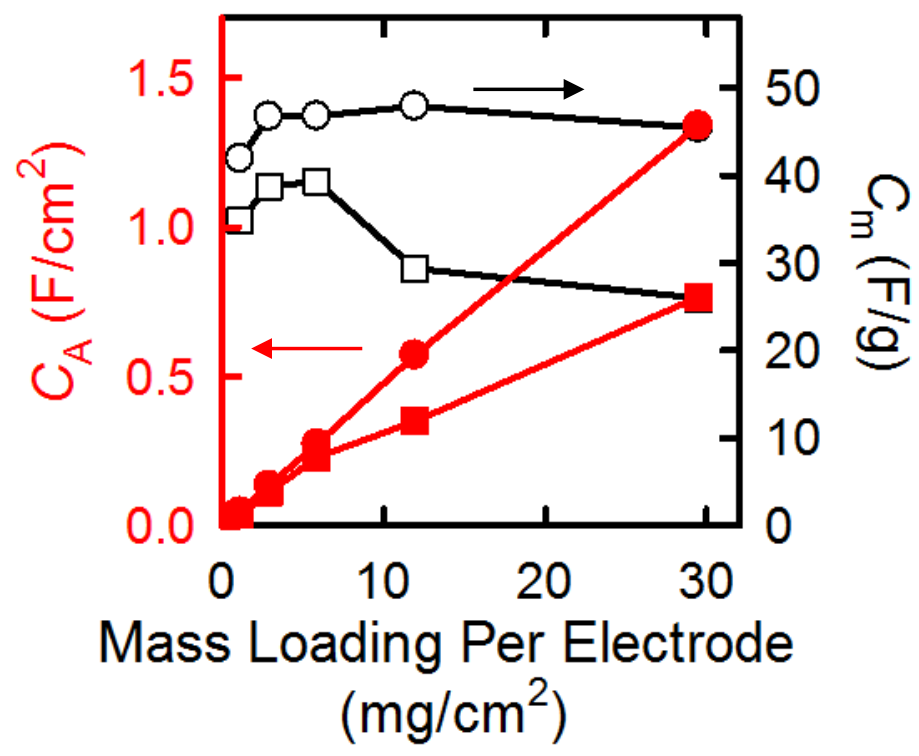

Figure S1. The relationship of gravimetric $\left(C_{\mathrm{m}}\right.$, black $)$ and areal $\left(C_{\mathrm{A}}\right.$, red $)$ capacitances calculated from the corresponding $\mathrm{CV}$ data, respectively, vs. $m_{\mathrm{A}}$ at scan rates of 10 (circles) and $100 \mathrm{mV} / \mathrm{s}$ (squares). 
Table S1. Gravimetric and areal performance of various graphene, graphene-like materials, and holey graphene based supercapacitor electrodes prepared from different processes.

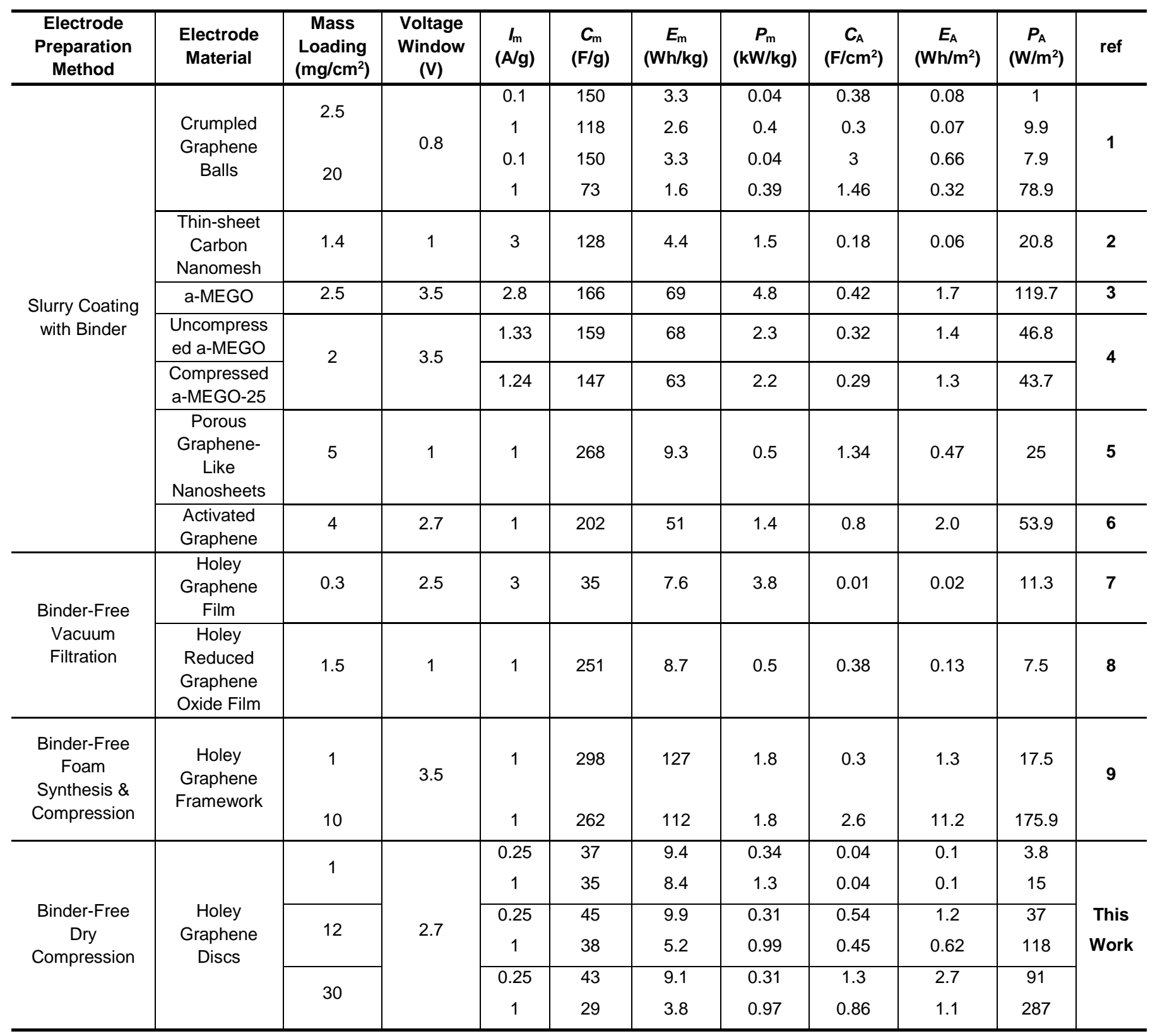

Note: (1) For references without specification of actual values, $E_{\mathrm{m}}$ and $P_{\mathrm{m}}$ were re-calculated using the same formula used in this work: $E_{\mathrm{m}}=(1 / 8) C_{\mathrm{m}} V^{2} ; P_{\mathrm{m}}=E_{\mathrm{m}} / \Delta t$, where $\Delta t$ is the discharge time. $\Delta t$ were back calculated from the reported $C_{\mathrm{m}}$ values (assuming for a single electrode) using $\Delta t=(1 / 4) C_{\mathrm{m}} V / I_{\mathrm{m}}$. (2) Most references did not directly provide areal-based data. The areal values shown were converted from the gravimetric data via $X_{\mathrm{A}}=X_{\mathrm{m}} \times m_{\mathrm{A}}$, where $X$ represents $C, E$, or $P$. (3) For the $\mathrm{E} / \mathrm{P}$ values calculated in this work, actual voltage window after consideration of $i \mathrm{R}$ drop was used. This resulted in overall underestimated values compared to other data in the Table, which used the maximum voltage window for the best estimation because it was difficult to obtain accurate $i \mathrm{R}$ values from most references. 


\section{References:}

1. Luo, J.; Jang, H. D.; Huang, J. Effect of Sheet Morphology on the Scalability of GrapheneBased Ultracapacitors. ACS Nano 2013, 7, 1464-1471.

2. Wang, H.; Zhi, L.; Liu, K.; Dang, L.; Liu, Z.; Lei, Z.; Yu, C.; Qiu, J. Thin-Sheet Carbon Nanomesh with an Excellent Electrocapacitive Performance. Adv. Funct. Mater. 2015, 25, 54205427.

3. Zhu, Y.; Murali, S.; Stoller, M. D.; Ganesh, K. J.; Cai, W.; Ferreira, P. J.; Pirkle, A.; Wallace, R. M.; Cychosz, K. A.; Thommes, M.; Su, D.; Stach, E. A. Ruoff, R. S. Carbon-Based Supercapacitors Produced by Activation of Graphene. Science 2011, 332, 1537-1541.

4. Murali, S.; Quarles, N.; Zhang, L. L.; Potts, J. R.; Tan, Z.; Lu, Y.; Zhu, Y.; Ruoff, R. S. Volumetric Capacitance of Compressed Activated Microwave-Expanded Graphite Oxide (aMEGO) Electrodes. Nano Energy 2013, 2, 764-768.

5. Sun, L.; Tian, C.; Li, M.; Meng, X.; Wang, L.; Wang, R.; Yin, J.; Fu, H. From Coconut Shell to Porous Graphene-Like Nanosheets for High-Power Supercapacitors. J. Mater. Chem. A 2013, $1,6462-6470$.

6. Zhang, L.; Zhang, F.; Yang, X.; Long, G.; Wu, Y.; Zhang, T.; Leng, K.; Huang, Y.; Ma, Y.; Yu, A.; Chen, Y. Porous 3D Graphene-Based Bulk Materials with Exceptional High Surface Area and Excellent Conductivity for Supercapacitors. Sci. Rep. 2013, 3, 1408.

7. Han, X.; Funk, M. R.; Shen, F.; Chen, Y.-C.; Li, Y.; Campbell, C. J.; Dai, J.; Yang, X.; Kim, J.-W.; Liao, Y.; Connell, J. W.; Barone, V.; Chen, Z.; Lin, Y.; Hu, L. Scalable Holey Graphene Synthesis and Dense Electrode Fabrication toward High-Performance Ultracapacitors. ACS Nano 2014, 8, 8255-8265.

8. Bai, Y.; Yang, X.; He, Y.; Zhang, J.; Kang, L.; Xu, H.; Shi, F.; Lei, Z.; Liu, Z.-H. Formation Process of Holey Graphene and Its Assembled Binder-Free Film Electrode with High Volumetric Capacitance. Electrochim. Acta 2016, 187, 543-561.

9. Xu, Y.; Lin, Z.; Zhong, X.; Huang, X.; Weiss, N. O.; Huang, Y.; Duan, X. Holey Graphene Frameworks for Highly Efficient Capacitive Energy Storage. Nat. Commun. 2014, 5, 4554. 